\title{
Population structure of Phytophthora capsici in the state of Tennessee
}

\author{
Timothy B. Siegenthaler ${ }^{1}\left[\right.$ ] Kurt Lamour $^{1}\left(\mathbb{D} \cdot\right.$ Zachariah R. Hansen $^{1}(\mathbb{D}$
}

Received: 17 May 2021 / Revised: 27 November 2021 / Accepted: 30 November 2021

(c) The Author(s) 2022

\begin{abstract}
The plant pathogen Phytophthora capsici can be found all throughout the USA, and the population genetics of this organism have been studied within many of these states. Until now, no work has been done in the state of Tennessee to investigate the population structure and genetics of $P$. capsici found there. The population structure of $P$. capsici was explored using 296 isolates collected from five counties in Tennessee in 2004, 2007, 2018, and 2019. Samples were genotyped using 39 single nucleotide polymorphism (SNP) genetic markers. Multiple analyses indicate that the population structure of $P$. capsici in Tennessee exists in isolated clusters structured by geography. Geographically separate populations were genetically distinct, suggesting there is limited or no outcrossing among populations, but there is significant sexual reproduction occurring within populations. These findings corroborate previous studies of $P$. capsici throughout the midwestern and northeastern USA, where populations are generally sexually reproducing and structured by geography. This study provides the first characterization of $P$. capsici population structure in Tennessee.
\end{abstract}

Keywords Oomycetes $\cdot$ SNP $\cdot$ Multi-locus genotyping $\cdot$ Population genetics

\section{Introduction}

Phytophthora blight of cucurbits and pepper is caused by the oomycete Phytophthora capsici and was first reported on pepper in the state of New Mexico in 1922 (Leonian 1922). The pathogen is now distributed across the USA and throughout the world (Gobena et al. 2012a; Hu et al. 2013). This disease can be devastating to the production of many vegetables such as pumpkin, squash, cucumbers, and peppers (Hausbeck and Lamour 2004; Granke et al. 2012). Symptoms of this disease include plant wilt, crown rot, stem rot, and fruit rot and can lead to complete crop loss. Phytophthora blight is a very challenging disease to manage primarily because of how it reproduces and is spread.

Infestation of a field may start with a very small number of asexual spores known as zoospores. One infected fruit may contain millions of sporangia, each filled with 20 to 40 zoospores which are released in the presence of water.

Section editor: Marco Thines

Zachariah R. Hansen

zhansen1@utk.edu

1 Department of Entomology and Plant Pathology, University of Tennessee, Knoxville, TN 37996, USA
Once infection of a new host occurs, the asexual cycle is repeated, leading to rapid dispersal of inoculum throughout a site, especially when a rain event or irrigation occurs. This means that a few genotypes may rapidly proliferate to dominate a field (Lamour and Hausbeck 2001b). If these individuals are fit and carry advantages such as fungicide resistance, an entire field of crops could be lost even with an organized plan of cultural and chemical control. In some parts of the world, such as China and Argentina, large portions of farmland are dominated by a few clonal populations (Gobena et al. 2012a; Hu et al. 2013). This is explained by mild or warm fallow seasons where zoospores are not killed by freezing winter temperatures. Contrary to that scenario, there is no evidence that these clonal populations survive from year to year through winter in the midwestern, northeastern, and southeastern USA (Dunn et al. 2010; Granke et al. 2012). In these areas, persistence of $P$. capsici is due to the production of oospores (Lamour and Hausbeck 2001a).

Phytophthora capsici is a heterothallic organism and has two mating types, A1 and A2. When opposite mating types come into contact, sexual reproduction can occur resulting in oospore formation. Oospores are thick-walled sexual spores that serve as overwintering structures, which contribute to reemergence of disease from year to year, and can remain viable in fallow soil for more than 5 years (Lamour 
and Hausbeck 2003). Additionally, there is the potential for formation of asexual survival spores, known as chlamydospores. Although these are uncommon in nature, chlamydospores can enable clonal lines to persist from year to year (Islam et al. 2005). The spread of these three types of propagules from one field to another occurs primarily by two methods: surface waterways and human transmission (Ristaino et al. 1993; Gevens et al. 2007). In large rain events, runoff from infested fields may spread to nearby fields, either across the soil surface or through a connecting watershed, such as an irrigation stream (Gevens et al. 2007). This can lead to the introduction of zoospores into new fields downstream of the primary infection. Humans can move these propagules through transport of infested soil on farm equipment, tools, and boots. Additionally, the spread of infected fruit and potentially seeds can lead to introduction to new locations. These methods occur over relatively short distances and require a significant mechanical form to enable spread and do not allow for even spread across very large areas of land, especially when compared with the wind transmission of other oomycetes such as Phytophthora infestans (Fry 2008; Granke et al. 2009). These modes of reproduction and spread of propagules influence the populations structure within and among populations in a region (Granke et al. 2009; Campbell and Ristaino 1999).

The population genetics of $P$. capsici has been a focus of many studies that began with the collection of isolates from specific locations or regions of interest. In these previous studies, isolates were genotyped using various genetic markers such as microsatellites (simple sequence repeats or SSRs), amplified fragment length polymorphisms (AFLPs), or single nucleotide polymorphisms (SNPs) (Dunn et al. 2010; Hu et al. 2013; Gobena et al. 2012a; Castro-Rocha et al. 2017). Information gained in such studies can provide insight into how $P$. capsici is spread throughout a region, what degree of gene flow there may be between locations, and whether populations are primarily reproducing clonally or sexually. From these types of studies, three primary population structures have been observed: widespread clonal populations, isolated sexual populations, and outcrossing sexual populations (Dunn et al. 2010; Hu et al. 2013; Gobena et al. 2012a; Castro-Rocha et al. 2017). These structures are greatly influenced by various factors such as weather, geography, agricultural practices, and regional crop history. Given this, it is important to treat each region differently and to avoid inferring the population structure of one location solely based on the observations of another. Little is known about the population genetics of $P$. capsici in Tennessee. The goals of this study were to (i) identify mating types of P. capsici isolates collected in Tennessee to determine A1:A2 mating-type ratios; (ii) identify multi-locus genotypes (MLGs) and compare diversity of these between sampling locations; (iii) determine if significant differences exist among populations; and (iv) document the structure of the populations to determine if sampling locations are genetically similar or significantly different.

\section{Materials and methods}

\section{Sample collections}

In 2018 and 2019, samples of pumpkin, squash, zucchini, and pepper showing signs or symptoms of $P$. capsici infection were collected from farms in five counties in middle and eastern Tennessee and taken to the laboratory for processing. In 2018, cuttings of lesions were surface sterilized using a $0.5 \%$ sodium hypochlorite solution, rinsed with sterile distilled water, and plated onto PARP-H medium ( $17 \mathrm{~g}$ cornmeal agar, $0.4 \mathrm{ml}$ pimaricin solution $(25 \mathrm{mg} / \mathrm{ml}), 250 \mathrm{mg}$ ampicillin, $1 \mathrm{ml}$ rifampicin solution $(10 \mathrm{mg} / \mathrm{ml}), 5 \mathrm{ml}$ PCNB solution $(5 \mathrm{mg} / \mathrm{ml})$, and $2 \mathrm{mg}$ hymexazol per 1 L) (Ferguson and Jeffers 1999). Plated samples were stored at $\sim 24^{\circ} \mathrm{C}$ in the dark for 1 to 2 days. From samples with mycelial growth, hyphal tip transfers were plated onto additional PARP-H medium. All cultures were re-isolated as singlezoospore isolates (2018) or hyphal tip transfers (2019) and stored following the methods of Siegenthaler and Hansen (2021). A total of 222 isolates of $P$. capsici were obtained from samples collected in 2018 and 2019. Additionally, data from 74 historical isolates, which were collected from one farm in Grainger County Tennessee in 2004 and 2007, were also included in the study. A total of 296 isolates were genotyped in the study. Ninety-two isolates were from Rhea County, TN, 49 from Bledsoe County, 43 from Putnam County, 38 from Lincoln County, and 74 from Grainger County (Table 1, Fig. 1).

\section{Preparation for DNA extraction}

A small amount of hyphal material was collected from each 2018 single-zoospore isolate and used to inoculate PARP-H broth aliquoted into a 24-well plate. Each plate was covered with a breathable sealing film and left to incubate at $24^{\circ} \mathrm{C}$. Plates were agitated twice daily for 5 to 7 days or until a mycelial mat formed on top of the broth. Mycelia were then transferred into 96 -well bead mill plates containing glass beads and stored at $-20{ }^{\circ} \mathrm{C}$ until further processing. For 2019 isolates, samples of infected plant tissue used for isolation were taken directly from lesions and placed into 96-well bead mill plates. Plates were stored in a $-20^{\circ} \mathrm{C}$ freezer until further processing.

\section{Mating type}

Mating types of all isolates were determined during the same year they were collected using previously described methods (Siegenthaler and Hansen 2021). Briefly, a 5-mm plug of each isolate with an unknown mating type was plated onto clarified 
Table 1 Collection information, genotypic diversity statistics, and mating type of Phytophthora capsici populations from Tennessee collected in 2004, 2007, 2018, and 2019

\begin{tabular}{|c|c|c|c|c|c|c|c|c|c|c|c|}
\hline \multirow[t]{2}{*}{ Pop $^{\mathrm{a}}$} & \multirow[t]{2}{*}{$\mathrm{N}^{\mathrm{b}}$} & \multirow[t]{2}{*}{$\mathrm{MLG}^{\mathrm{c}}$} & \multirow[t]{2}{*}{$\mathrm{eMLG}^{\mathrm{d}}$} & \multirow[t]{2}{*}{$\lambda^{\mathrm{e}}$} & \multirow[t]{2}{*}{$\lambda \mathrm{C}^{\mathrm{f}}$} & \multirow[t]{2}{*}{$\mathrm{G}^{\mathrm{g}}$} & \multicolumn{2}{|c|}{ Mating type } & \multirow[t]{2}{*}{$\chi^{2 \mathrm{~h}}$} & \multirow[t]{2}{*}{$P^{i}$} & \multirow[t]{2}{*}{ Collection date } \\
\hline & & & & & & & A1 & A2 & & & \\
\hline R18 & 20 & 18 & 17 & 0.94 & 0.98 & 16.6 & 14 & 10 & 0.67 & $\mathrm{~ns}$ & 8/9/2018 \\
\hline R19 & 72 & 56 & 17 & 0.97 & 0.90 & 43.9 & 30 & 46 & 3.37 & ns & $8 / 31 / 2019$ \\
\hline B18 & 19 & 10 & 10 & 0.83 & 0.87 & 5.9 & 7 & 13 & 1.8 & $\mathrm{~ns}$ & $9 / 7 / 2018$ \\
\hline B19 & 30 & 3 & 2 & 0.32 & 0.33 & 1.4 & 32 & 0 & 32 & 0.001 & $10 / 11 / 2018$ \\
\hline P18 & 43 & 10 & 6 & 0.73 & 0.75 & 3.7 & 14 & 29 & 5.23 & 0.05 & $8 / 31 / 2018$ and $11 / 16 / 2018$ \\
\hline L19 & 38 & 21 & 13 & 0.93 & 0.96 & 15.7 & 14 & 23 & 2.19 & $\mathrm{~ns}$ & 9/12/2019 \\
\hline G04 & 23 & 19 & 16 & 0.93 & 0.97 & 15.1 & 17 & 6 & 5.26 & 0.05 & $2004^{\mathrm{j}}$ \\
\hline G07 & 51 & 50 & 18 & 0.98 & 0.99 & 49.0 & 26 & 25 & 0.02 & ns & $2007^{\mathrm{j}}$ \\
\hline Total & 296 & 187 & - & - & - & - & $154^{\mathrm{k}}$ & $152^{\mathrm{k}}$ & 0.01 & ns & - \\
\hline
\end{tabular}

${ }^{\text {a }}$ Populations are labeled with a single letter signifying the collection county followed by collection year: $R$ Rhea, $B$ Bledsoe, $P$ Putnam, $L$ Lincoln, and $G$ Grainger

${ }^{\mathrm{b}}$ Number of isolates collected from each county and year

${ }^{c}$ Number of multi-locus genotypes (MLGs) per county and year

${ }^{\mathrm{d}}$ The number of expected MLGs at the smallest sample size $\geq 10$ based on rarefaction

eSimpson's index (Simpson 1949)

${ }^{\text {f }}$ Simpson's index (Simpson 1949), adjusted for sampling size

${ }^{g}$ Stoddart and Taylor's index of MLG diversity (Stoddart and Taylor 1988)

${ }^{\mathrm{h}}$ Chi-square statistic testing whether mating types at each site are 1:1

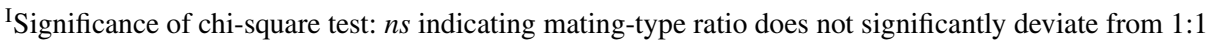

${ }^{\mathrm{j}}$ Exact collection dates are unknown

${ }^{\mathrm{k}}$ Mating type totals include data from isolate which were not genotyped for this study

V8 with another 5-mm plug of an isolate of a known mating type. Plates were incubated for 5 to 7 days, and then viewed under a compound microscope to look for oospores. The presence of oospores indicated that the unknown isolate's mating type was compatible with (i.e., the opposite of) the known isolate's mating type.

\section{DNA extraction}

Mycelium or plant tissue was freeze-dried in the 96-well bead plate and processed to a fine powder using a Mixer Mill (Qiagen, Germantown, MD, USA). The powder was processed using a MagMAX DNA Multi-Sample Ultra 2.0
Kit according to the manufacturer's directions (Thermo Fisher, Waltham, MA, USA) and the resulting DNA quantified using a Qubit device according to the manufacturer's directions (Thermo Fisher, Waltham, MA, USA).

\section{PCR and sequencing}

Approximately $1000 \mathrm{ng}$ of DNA for each sample was submitted to Floodlight Genomics LLC (Knoxville, TN, USA) for targeted sequencing. Thirty-nine SNP markers were amplified from the nuclear genome using different speciesspecific primers for each site as described previously (CastroRocha et al. 2017). These were processed using an optimized

\section{Tennessee}

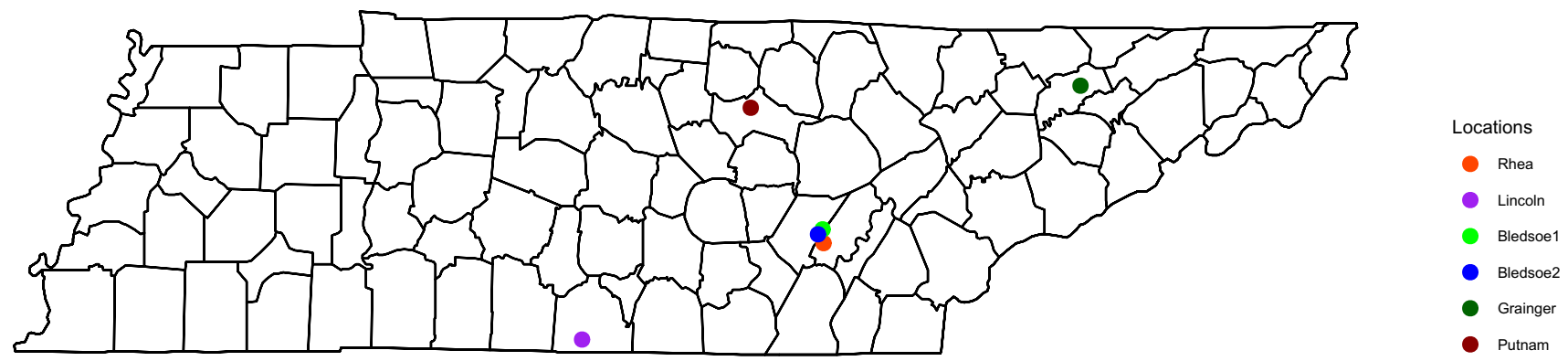

Fig. 1 Map of Tennessee and the locations isolates were collected from in 2004, 2007, 2018, and 2019 
Hi-Plex approach, which includes multiplex PCR amplification of each sample and sequencing of the targets using the Illumina HiSeq X platform. Floodlight Genomics delivered sample-specific raw sequence reads.

\section{Sequence alignment and variant calling}

The sample-specific reads were aligned to their target sequences using CLC Genomics Workbench version 9.5.3 using default settings. Variant sites were assessed using the quality-based variant detection (QVD) workflow with settings to require at least $40 \mathrm{X}$ coverage. The QVD settings are as follows: neighborhood radius $=5$, maximum gap and mismatch $\operatorname{count}=2$, minimum neighborhood quality $=15$ and minimum central quality $=20$ with minimum coverage $=40$, minimum variant frequency $=25 \%$, minimum expected alleles $=2$, and standard genetic code. Variant Call Format (VCF) sheets were produced for each sample and processed in Excel (Microsoft) to extract the genotypes for further downstream analyses. Loci were considered heterozygous if the alternate allele had a frequency of at least $25 \%$.

\section{Data analyses}

Genetic data were analyzed using the excel plugin GENALEX 6.5, R version 3.6.1 (R Core Team 2019) and the R package Poppr version 2.8.6 (Kamvar et al. 2014, 2015). GENALEX 6.5 was used to format the data so it could be read and made an object within R and for calculating pairwise $F_{\text {ST }}$ population comparisons. Hardy-Weinberg equilibrium was assessed using the function hw.test from the 'pegas' package (Paradis 2010). Using Poppr, the number of multi-locus genotypes (MLGs) per sampling location and year were identified. Isolates sharing MLGs were considered clones and data were clone corrected to account for these. To further understand the overall diversity of the samples collected in TN, Simpson's index and Stoddart and Taylor's index were calculated (Simpson 1949; Stoddart and Taylor 1988). Data were also analyzed by discriminant analysis of principal components (DAPC). In the DAPC, populations were assigned by county and year as predefined inputs. Following the protocol described in the Poppr primer, developed by Kamvar et al., a DAPC cross validation was performed with $1000 \times$ replication and an optimal number of principal components to be retained were 20 , as well as retaining 500 discriminant components (DC). The results from the DAPC cross validation were then plotted as a scatter plot. A minimum spanning network (MSN) was constructed to compliment the findings from the DAPC. This MSN was developed using the interactive tool provided through Poppr using Provesti's genetic distance. To detect population differentiation, analysis of molecular variance
(AMOVA) was performed with additional significance testing through randomization tests (Excoffier et al. 1992).

\section{Results}

\section{Genetic diversity}

A total of 187 unique multi-locus genotypes (MLGs) and 109 repeated MLGs were identified (Table 1). One MLG was shared between two locations, Bledsoe 2018 (B18) and Putnam 2018 (P18). No MLGs that were found in any 2018 population were detected in 2019. Populations from Rhea 2018 (R18), Rhea 2019 (R19), Lincoln 2019 (L19), Grainger 2004 (G04), and Grainger 2007 (G07) contained the majority of these unique MLGs and were more diverse than Bledsoe 2018 (B18), Bledsoe 2019 (B19), and Putnam 2018 (P18). The disparity in genotypic diversity is reflected in the Stoddart and Taylor's index and Simpson index values calculated for each population, where R18, R19, L19, G04, and G07 all have indices that are much greater than that of B18, B19, and P18 (Table 1).

\section{Mating types and Hardy-Weinberg equilibrium}

In all populations excluding B19, P19, and G04, the A1:A2 ratios did not differ significantly from 1:1. B19 was the only population that did not have isolates of both mating types. In a population-wise comparison of Hardy-Weinberg equilibrium (HWE) statistics for all 39 loci and the eight populations, approximately $30 \%$ of loci significantly departed from the expectations HWE (Fig. 2).

\section{Population structure}

Discriminant analysis of principal components (DAPC) grouped most isolates from the same county and the same year together. Isolates collected from the same county, but different year, were genetically similar as shown by the R19 and R18 or the G04 and G07 clusters (Fig. 3). DAPC indicated that isolates that were geographically different are also genetically different. Similarly, geographically similar isolates have more genetic similarities. This suggests that the general population is structured by geographic location and that each sampling location is distinct from one another. The minimum spanning network (MSN) supports this result by illustrating that, in general, isolates from different counties are genetically distant from one another (Fig. 4). In a pairwise comparison of $F_{\text {ST }}$ statistics, all populations were statistically different at $P$ value $<0.05$, including isolates collected within the same field but in different years. Isolates collected within the same field in different years did have lower $F_{\mathrm{ST}}$ values 


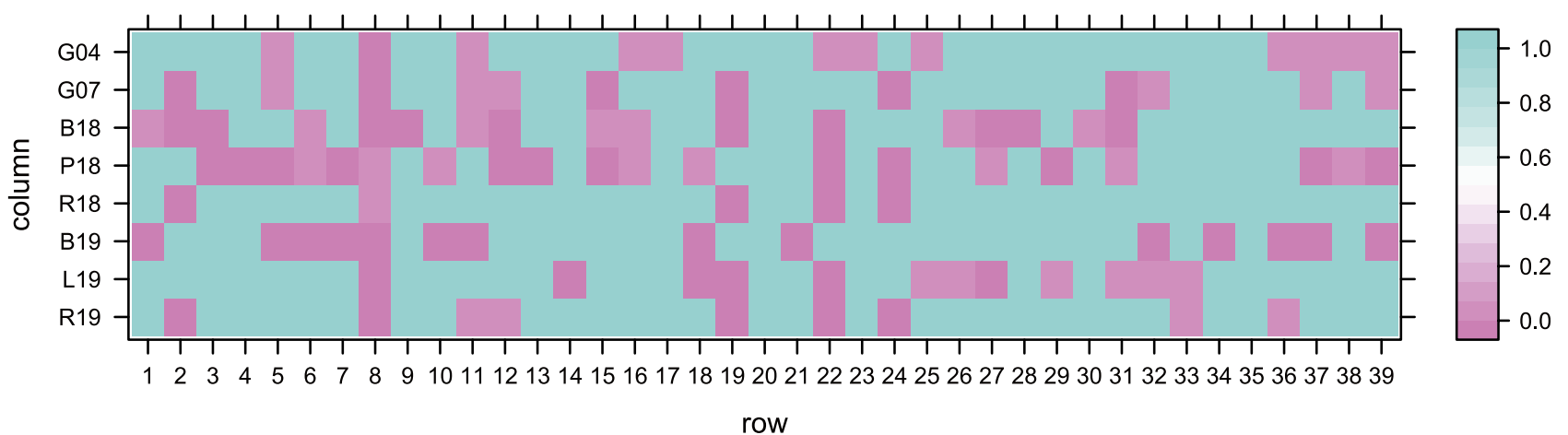

Fig. 2 Heatmap of population-wise $P$ value comparisons of HardyWeinberg statistics between Tennessee $P$. capsici populations and SNP markers. Rows (y-axis) represent $P$. capsici populations in TN and columns (x-axis) represent the 39 SNP markers used in the study. All loci marked with pink are suspected of not being in HWE

such a 0.03 for R18 and R19, compared to 0.46 for B19 and L19 (Table 2). The analysis of molecular variance (AMOVA) also supports these results, where a significant amount of variation was detected between populations $(17 \%, P=0.001)$ and within populations $(83 \%, P=0.001)$ (Table 3).

\section{Discussion}

Our analysis indicates that populations of $P$. capsici in Tennessee are genetically isolated. This is similar to a study by Dunn et al., 2012, where populations of $P$. capsici throughout New York were genetically diverse and clustered by geographic location. Quesada-Ocampo et al. with $P \leq 0.05$. Population abbreviations are written as the county where isolates were collected followed by the year of collection, where $\mathrm{G}=$ Greene County, $\mathrm{B}=$ Bledsoe County, $\mathrm{P}=$ Putnam County, $\mathrm{R}=$ Rhea County, and $\mathrm{L}=$ Lincoln County

(2011) and Lamour and Hausbeck (2001b) also found that $P$. capsici populations were structured by geographic location and were clearly distinct from one another. This trend has also been observed in Mexico, where CastroRocha et al. (2016) reported a high proportion of unique MLGs and little gene flow between locations. This contrasts with other studies where there was evidence of outcrossing populations with significant numbers of shared clonal genotypes across farms in Massachusetts and Long Island, New York (Gobena et al., 2012b; Castro-Rocha et al., 2017). Like these studies, we identified isolates of both mating types A1 and A2, providing evidence of sexual reproduction within most Tennessee populations of $P$. capsici. Phytophthora capsici is not dispersed long distances by air (Granke et al. 2009). Therefore, genotypes
Fig. 3 Discriminant analysis of principal components (DAPC) of all $P$. capsici isolates collected in 2004, 2007, 2018, and 2019. Rhea 2019 (R19), Lincoln 2019 (L19), Bledsoe 2019 (B19), Rhea 2018 (R18), Putnam 2018 (P18), Bledsoe 2018 (B18), Grainger 2007 (G07), and Grainger 2004 (G04)

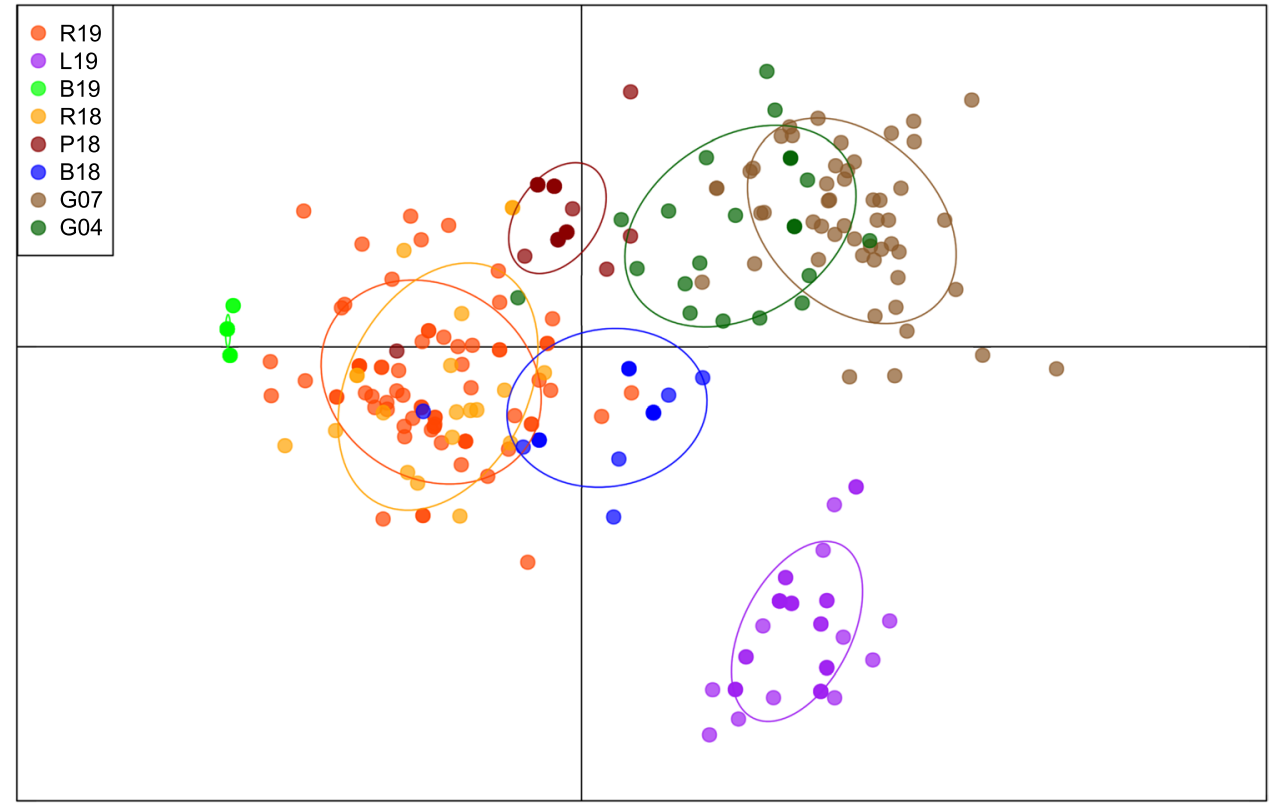


Fig. 4 Minimum spanning network of Tennessee $P$. capsici populations constructed using the Provesti's distance
POPULATION

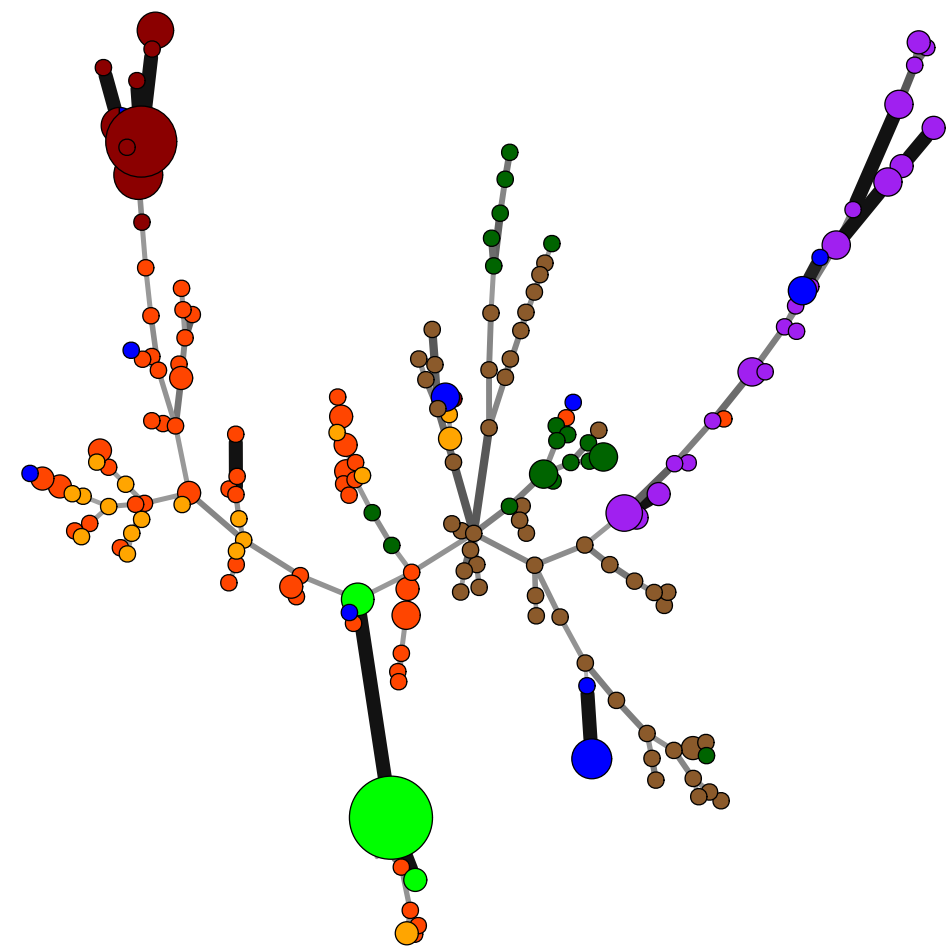

generally have a limited geographic distribution in the absence of another dispersal mechanism, like surface water. The distance separating populations in our study explains why the populations were genetically distinct. Our collection sites were separated by approximately 180 to $275 \mathrm{~km}$, except for Bledsoe and Rhea Counties which are adjacent. The distance separating collection sites reduces the likelihood of genotypes being shared across sampling locations. Although Bledsoe and Rhea Counties are adjacent, the sampling sites were not adjacent farms and were not directly connected by surface waterways.
This is in contrast to the study by Gobena et al. (2012b), where clonal genotypes were readily detected at multiple sampling sites, but all sampling sites were either adjacent farms or within $25 \mathrm{~km}$ of each other. The authors suggest that there is likely significant local spread via surface water in the eastern end of Long Island, New York.

Populations P18 and B19 had significantly lower MLG diversity than other regions and contained large numbers of clonal genotypes. This was reflected by the mating-type ratios of these populations, which were highly skewed to A1 or A2, rather than the expected 1:1 ratio for a sexually
Table 2 Pairwise comparison of $F_{\mathrm{ST}}$ values of Phytophthora capsici populations sampled from eight counties in Tennessee from 2004, 2007, 2018, and 2019

\begin{tabular}{|c|c|c|c|c|c|c|c|}
\hline \multicolumn{8}{|l|}{$F_{\mathrm{ST}}$ values } \\
\hline Populations $^{\mathrm{a}}$ & R19 & L19 & B19 & R18 & P18 & B18 & G04 \\
\hline R19 & 0 & & & & & & \\
\hline L19 & 0.24 & 0 & & & & & \\
\hline B19 & 0.17 & 0.46 & 0 & & & & \\
\hline R18 & $0.03^{\mathrm{b}}$ & 0.27 & 0.23 & 0 & & & \\
\hline P18 & 0.16 & 0.34 & 0.37 & 0.19 & 0 & & \\
\hline B18 & 0.13 & 0.20 & 0.30 & 0.11 & 0.22 & 0 & \\
\hline G04 & 0.14 & 0.24 & 0.33 & 0.17 & 0.23 & 0.13 & 0 \\
\hline G07 & 0.20 & 0.23 & 0.37 & 0.21 & 0.27 & 0.16 & 0.07 \\
\hline
\end{tabular}

${ }^{\text {a }}$ Populations are labeled with a single letter signifying the collection county followed by collection year: $R$ Rhea, $B$ Bledsoe, $P$ Putnam, $L$ Lincoln, and $G$ Grainger

${ }^{\mathrm{b}} F_{\mathrm{ST}}$ values were calculated in GenAlex 6.5 with distances between populations based on AMOVA of each population. All values were significantly different from zero at $P<0.001$, using 999 permutations, unless indicated otherwise 
Table 3 Analysis of molecular variance (AMOVA) for clone-corrected samples of Phytophthora capsici from Tennessee collected in years 2004, 2007, 2018, and 2019

\begin{tabular}{lllccc}
\hline Source of variation & df & Sum of squares & Variance components & Percentage of variation $^{P \text { value }}$ \\
\hline Between populations & 7 & 905 & 2.71 & 17 & 0.001 \\
Within populations & 187 & 2490 & 13.31 & 83 & 0.001
\end{tabular}

${ }^{\text {a }} P$ values based on randomized significance testing performed to test the significance of the variance components

reproducing population. This is likely explained by the seasonal cycle of $P$. capsici reproduction and spread. In Tennessee, where winter temperatures reach freezing, $P$. capsici's asexual spores do not survive from one growing season to another, except when chlamydospores are produced, which is uncommon (Islam et al. 2005). Therefore, oospores are the primary inoculum and, following infection, asexual sporangia and zoospores are responsible for secondary disease spread. Similar patterns were found by Gobena et al. (2012b). As the season progresses, fit genotypes dominate a field, and the observable genetic diversity decreases. This is reflected in the populations P18 and B19, where isolates were collected later in the growing season, after harvest, when only culls and late-ripening fruit were left in the field. This is the most likely explanation for the lack of diversity given there was no evidence of clonal genotypes persisting from 2018 to 2019. These results contrast those found in places such as China and Argentina, where large clonal populations persist from year to year (Hu et al. 2013; Gobena et al. 2012a). These locations have mild or warm fallow seasons, allowing for the persistence of clonal genotypes, in contrast to the freezing temperatures of Tennessee winters.

One unexpected result was that one MLG was shared between two counties that were geographically distant. This MLG was found five times across the state, with four from P18 and one from B18. Even if the two populations are descended from a single founder population, the possibility of finding the same genotype at both locations could only be explained through the movement of plant material, soil, or water. This seems unlikely given the large amount of geographic distance between locations, but this cannot be ruled out. Most likely, this event is explained by a labeling error somewhere in the workflow, which placed the one isolate from B18 into the $\mathrm{P} 18$ population.

Ultimately, this study supports and is consistent with current knowledge about $P$. capsici populations in the USA. Like Dunn et al. (2010), our results suggest that spread is limited between locations and that populations are genetically distinct. Our findings support pathogen dispersal mitigation as the most important strategy for disease management. It is imperative to limit behavior that may aide in the spread of this pathogen. Cleaning and washing equipment, tools, and boots worn by workers is important.
It is also crucial to ensure that clean seed, transplants, and irrigation water are used when growing susceptible vegetable crops (Granke et al. 2012; Jones et al. 2014). Dispersal mitigation also is important in reducing the spread of fungicide resistance, which was recently documented in Tennessee (Siegenthaler and Hansen 2021). Overall, this study provides a characterization of $P$. capsici population structure in Tennessee, and provides useful information for agricultural professionals and researchers to better understand and further explore the persistence, dispersal, and evolution of $P$. capsici in Tennessee and the southeastern USA.

Acknowledgements We would like to acknowledge the University of Tennessee's Department of Entomology and Plant Pathology for providing funding to support this research. Additionally, we would like to thank all the growers and county extension agents who graciously allowed us to sample from their farms and volunteered their time.

Author contribution TBS-collected isolates, conducted experiments and analyses, primary manuscript author. KL-performed isolate genotyping, organized raw genotype data, assisted with manuscript preparation. $\mathrm{ZRH}$ - conceived the study, assisted with data analysis and interpretation, assisted with manuscript preparation.

Funding The University of Tennessee's Department of Entomology and Plant Pathology and Floodlight Genomics LLC provided all genetic amplification and sequencing for free as part of their Educational and Research Outreach Program (EROP).

Data availability Not applicable.

Code availability Not applicable.

\section{Declarations}

Ethics approval Not applicable.

Consent to participate Not applicable.

Consent for publication Not applicable.

Conflict of interest The authors declare no competing interests.

Open Access This article is licensed under a Creative Commons Attribution 4.0 International License, which permits use, sharing, adaptation, distribution and reproduction in any medium or format, as long as you give appropriate credit to the original author(s) and the source, provide a link to the Creative Commons licence, and indicate if changes 
were made. The images or other third party material in this article are included in the article's Creative Commons licence, unless indicated otherwise in a credit line to the material. If material is not included in the article's Creative Commons licence and your intended use is not permitted by statutory regulation or exceeds the permitted use, you will need to obtain permission directly from the copyright holder. To view a copy of this licence, visit http://creativecommons.org/licenses/by/4.0/.

\section{References}

Campbell CL, Ristaino JB (1999) The importance of dispersal mechanisms ithe epidemiology of phytophthora blights and downy mildews on crop plants. Ecosyst Health 5:146-157. https://doi.org/ 10.1046/j.1526-0992.1999.09924.x

Castro-Rocha A, Shrestha S, Lyon B, Grimaldo-Pantoja GL, FloresMarges JP, Valero-Galván J, Aguirre-Ramírez M, Osuna-Ávila P, Gómez-Dorantes N, Ávila-Quezada G, Luna-Ruíz JJ, RodríguezAlvarado G, Fernández-Pavía SP, Lamour KH (2016) An initial assessment ofgenetic diversity for Phytophthora capsici in northern and central Mexico. Mycol Prog 15:15. https://doi.org/10.1007/ s11557-016-1157-0g/10.1007/s11557-016-1157-0

Castro-Rocha A, Hulvey J, Wick R, Shrestha S, Lamour K (2017) Genetic diversty of Phytophtora capsici recovered from Massachusettss between 1997 and 2014. Mycol Prog 16:999-1006. https://doi.org/ 10.1007/s11557-017-1334-9

Dunn AR, Milgroom MG, Meitz JC, McLeod A, Fry WE, McGrath MT, Dillard HR, Smart CD (2010) Population structure and resistance to mefenoxam of Phytophthora capsici in New York State. Plant Dis 94:1461-1468. https://doi.org/10.1094/ PDIS-03-10-0221

Excoffier L, Smouse PE, Quattro JM (1992) Analysis of molecular variance inferred from metric distances among DNA haplotypes: application to human mitochondrial DNA restriction data. Genetics 131:479-491

Ferguson AJ, Jeffers SN (1999) Detecting multiple species of Phytophthora in container mixes from ornamental crop nurseries. Plant Dis 83:1129-1136. https://doi.org/10.1094/pdis.1999.83.12.1129

Fry W (2008) Phytophthora infestans: the plant (and R gene) destroyer. Mol Plant Pathol 9(3):385-402. https://doi.org/10.1111/j.13643703.2007.00465.x

Gevens AJ, Donahoo RS, Lamour KH, Hausbeck MK (2007) Characterization of Phytophthora capsici from Michigan surface irrigation water. Phytopathology 97:421-428

Gobena D, Roig J, Galmarini C, Hulvey J, Lamour K (2012a) Genetic diversity of Phytophthora capsici isolates from pepper and pumpkin in Argentina. Mycologia 104:102-107. https://doi.org/10. 1007/s11557-016-1157-0

Gobena D, McGrath M, Lamour K (2012b) Survival and spread of Phytophthora capsici on Long Island, New York. Mycol Prog 11:761-768. https://doi.org/10.1007/s11557-011-0787-5

Granke LL, Quesada-ocampo L, Lamour K, Hausbeck MK (2012) Advances in research on Phytophthora capsici on vegetable crops in the United States. Plant Dis 95:1588-1600. https://doi.org/10. 1094/PDIS-02-12-0211-FE

Granke LL, Windstam ST, Hoch HC, Smart CD, Hausbeck MK (2009) Dispersal and movement mechanisms of Phytophthora capsici sporangia. Phytopathology 99:1258-1264. https://doi.org/10. 1094/phyto-99-11-1258
Hausbeck MK, Lamour KH (2004) Research progress and management challenges Phytophthora capsici on vegetable crops. Plant Dis 88:1292-1303. https://doi.org/10.1094/PDIS.2004.88.12.1292

Hu J, Pang Z, Bi Y, Shao J, Diao Y, Guo J, Yonggang L, Lv H, Lamour K, Liu X (2013) Genetically diverse long-lived clonal lineages of Phytophthora capsici from pepper in Gansu, China. Phytopathology 103:920-926. https://doi.org/10.1094/phyto-01-13-0016-r

Islam SZ, Babadoost M, Lambert KN, Ndeme A, Fouly HM (2005) Characterization of Phytophthora capsici isolates from processing pumpkin in Illinois. Plant Dis 89:191-197. https://doi.org/10. 1094/pd-89-0191

Jones LA, Worobo RW, Smart CD (2014) UV light inactivation of human and plant pathogens in unfiltered surface irrigation water. Appl Environ Microbiol 80:849-854. https://doi.org/10.1128/aem. 02964-13

Lamour K, Hausbeck MK (2003) Effect of crop rotation on the survival of Phytophthora capsici and sensitivity to mefenoxam. Plant Dis 12:841-845. https://doi.org/10.1094/PDIS.2003.87.7.841

Lamour KH, Hausbeck MK (2001a) The dynamics of mefenoxam insensitivity in a recombining population of Phytophthora capsici characterized with amplified fragment length polymorphism markers. Phytopathology 91:553-557. https://doi.org/10.1094/ PHYTO.2001.91.6.553

Lamour KH, Hausbeck MK (2001b) Investigating the spatiotemporal genetic structure of Phytophthora capsici in Michigan. Phytopathology 91:973-980. https://doi.org/10.1094/PHYTO.2001.91. 10.973

Kamvar ZN, Tabima JF, Grünwald NJ (2014) Poppr: an R package for genetic analysis of populations with clonal, partially clonal, and/or sexual reproduction. PeerJ 2:281. https://doi.org/10.7717/ peerj. 281

Kamvar ZN, Brooks JC, Grünwald NJ (2015) Novel R tools for analysis of genome-wide population genetic data with emphasis on clonality. Front Genet 6:208. https://doi.org/10.3389/fgene.2015.00208

Leonian L (1922) Stem and fruit blight of peppers caused by Phytophthora capsici sp. nov. Phytopathology 12:401-408

Paradis E (2010) pegas: an R package for population genetics with an integrated-modular approach. Bioinformatics 26:419-420

Quesada-Ocampo LM, Granke LL, Hausbeck MK (2011) Temporal genetic structure of Phytophthora capsici populations from a creek used for irrigation in Michigan. Plant Dis 95:1358-1369. https://doi.org/10.1094/PDIS-03-11-0191

R Core Team (2019) R: A language and environment for statistical computing. R Foundation for Statistical Computing, Vienna, Austria. https://www.R-project.org/. Accessed Sept 2018

Ristaino JB, Larkin RP, Campbell CL (1993) Spatial and temporal dynamics of Phytophthora epidemics in commercial bell pepper fields. Phytopathology 83:1312-1320

Siegenthaler T, Hansen Z (2021) Sensitivity of Phytophthora capsici from Tennessee to mefenoxam, fluopicolide, oxathiapiprolin, dimethomorph, mandipropamid, and cyazofamid. Plant Dis. https://doi.org/10.1094/PDIS-08-20-1805-RE

Simpson EH (1949) Measurement of diversity. Nature 163:688

Stoddart JA, Taylor JF (1988) Genotypic diversity: estimation and prediction in samples. Genetics 118:705-711

Publisher's Note Springer Nature remains neutral with regard to jurisdictional claims in published maps and institutional affiliations. 